\title{
Dinâmica migratória e o processo de ocupação do Centro-Oeste brasileiro: o caso de Mato Grosso
}

\author{
José Marcos Pinto da Cunha*
}

\begin{abstract}
Uma das últimas áreas de fronteira do país, o Estado de Mato Grosso é ainda hoje uma possibilidade para a população que busca alternativas para a migração. Paralelamente ao processo de "urbanização da fronteira", assiste-se em Mato Grosso outras iniciativas com impactos importantes, que dão novas especificidades ao reordenamento da população no território e também às perspectivas de continuidade de ocupação demográfica do Estado, como os assentamentos agrícolas e novas frentes pioneiras. Após ter apresentado um forte processo de ocupação até meados dos anos 80, Mato Grosso experimenta um visível arrefecimento do seu crescimento demográfico, contudo mantendo áreas ainda com relativo dinamismo. Ancorado na análise de dados dos Censos Demográficos e Agropecuários e em entrevistas realizadas no Estado, este artigo centra-se na análise das tendências migratórias e seus impactos no processo de ocupação do espaço matogrossense nos últimos vintes anos, com ênfase no comportamento de algumas áreas representativas dos principais processos em curso, buscando situá-las no contexto mais amplo de mudanças nos padrões de ocupação econômica. As análises mostram, por um lado, uma forte associação entre ambos os fenômenos, a partir do impacto das atividades extensivas (pecuária, soja, algodão) na redução das possibilidades de absorção dos migrantes no meio rural, e, por outro, os efeitos "compensadores" dos assentamentos de reforma agrária.
\end{abstract}

Palavras-chave: Migração interna. Fronteira agrícola. Distribuição da População. Condicionantes da migração. Mato Grosso.

\section{Introdução}

Embora o Mato Grosso tenha uma história de ocupação complexa, pode-se dizer que este Estado começa a despontar no cenário brasileiro a partir do avanço da frente pioneira paulista, em meados do século 20. Em um primeiro momento, este avanço provocou a ocupação no norte do Paraná, expandindo-se, posteriormente, para o sul do antigo Estado de Mato Grosso, com a pecuária de corte. Em seguida, nos anos 60, houve a entrada de gaúchos e paranaenses que se dedicavam à cultura do trigo e da soja (IPEA e FJN, 1997).

A dinâmica socioeconômica e a configuração espacial observadas no caso de Mato Grosso assemelham-se bastante a "fases" já verificadas em outros Estados da região Centro-Oeste - como Goiás ou Mato

\footnotetext{
*Demógrafo, professor do Departamento de Demografia (IFCH) e pesquisador do Nepo, ambos da Unicamp.

O autor agradece a inestimável colaboração das assistentes de pesquisa Gisele Maira Ribeiro de Almeida, Fernanda Raquel e Pollyana Carvalho. Este estudo contou com o apoio do CNPq e do Programa Pronex/CNPq.
} 
Grosso do Sul -, que tiveram a ocupação de seus territórios anteriormente. No entanto, para o Estado de Mato Grosso, evidenciase uma maior intensificação do processo de ocupação demográfica e econômica recente, acarretando, de forma muito mais precoce, os impactos de grandes transformações na estrutura produtiva e fundiária regional, o que teve importantes implicações sobre sua dinâmica migratória.

Tais impactos podem ser percebidos através de dois aspectos principais: a redução significativa dos fluxos migratórios para a área, nas últimas décadas (80 e 90); e as características e formas de inserção produtiva do migrante.

Do mesmo modo, este processo de transformação pode ser percebido no âmbito intra-estadual, com relação ao comportamento demográfico dos vários subespaços do Estado, cujas trajetórias refletem as diferenças regionais e as peculiaridades das diversas microrregiões, seja em termos do processo de ocupação econômica, seja através dos momentos de ocupação da fronteira agrícola. Fica claro nas análises que a forma como tradicionalmente o Mato Grosso foi ocupado vem se esvaindo gradativamente, principalmente à medida que a inserção dos migrantes torna-se cada vez mais difícil, considerando-se as novas e mais vigorosas formas de ocupação econômica do território.

Além dessa redução da intensidade e do volume da imigração para Mato Grosso, evidencia-se também um incremento da emigração para fora do Estado. As informações analisadas a este respeito mostram duas características distintas: por um lado, boa parte desta emigração ( $54 \%$ do total nos anos 90) refere-se, na verdade, a um retorno de grandes contingentes de pessoas que haviam procurado o Estado como uma alternativa para suas reproduções sociais; por outro, verifica-se que outra parte significativa desta emigração corresponde a um movimento que, ao longo da pesquisa, se rotulou de "caminho ou trilha da fronteira"
(CUNHA, 2002; CUNHA, ALMEIDA e RAQUEL, 2002; CUNHA e SILVEIRA, 1999), ou seja, não se trata propriamente de um processo de evasão demográfica de nativos ou moradores mais antigos, mas sim de uma redistribuição espacial da população migrante, que, em função de fatores de mudança, para utilizar a terminologia de Singer (1980), se vê obrigada a procurar novos lugares para o possível assentamento "definitivo". ${ }^{1}$

Em suma, o que se percebe em Mato Grosso é que este Estado, hoje, particularmente em termos migratórios, está muito aquém daquilo que foi na década de 70 e parte dos anos 80 , fruto do progressivo desaparecimento de um dos fatores que mais contribuíram para a sua ocupação: a expansão e/ou manutenção das áreas de fronteira agrícola. Não é por acaso que o Estado, atualmente, apresenta elevado grau de urbanização, onde os centros urbanos tornaram-se as últimas opções para a permanência dos migrantes ali chegados, situação que se agrava quando se considera o reduzido potencial de absorção demográfica da maioria deles.

\section{Mato Grosso: uma breve contextuali- zação do seu processo de ocupação territorial}

A região Centro-Oeste e, particularmente, o Mato Grosso possuem uma economia com caráter essencialmente agrícola e urbanização crescente, mas ainda com extensas áreas de matas e florestas. Estas características formam o retrato da sua diversidade demográfica e ambiental, que são capazes de explicar seu grande dinamismo econômico nos últimos anos.

$\mathrm{Na}$ década de 60, a Região CentroOeste iniciou um processo de modificação de sua estrutura produtiva, impulsionada pela ação estatal através dos programas de incentivo à modernização agropecuária e integração da região aos outros mercados, elementos que tiveram importantes

\footnotetext{
${ }^{1}$ Em trabalho anterior (CUNHA, 2001), utilizou-se a expressão "conto sem fim" para a situação de muitos colonos ou pequenos proprietários que, na trilha da fronteira, se vêem periodicamente forçados a se deslocarem para outras áreas, em geral, mais distantes e inóspitas.
} 
conseqüências em sua dinâmica demográfica e no processo de redistribuição espacial da população.

Esta ação estatal explicita-se através da preocupação de integração nacional do regime militar, o que justifica os representativos investimentos em grandes projetos agropecuários. "Enquanto a sociedade brasileira era duramente reprimida pelos governos militares que sucederam no poder nesse período, o Araguaia, o Mato Grosso e a Amazônia foram invadidos pelos grandes grupos econômicos através dos projetos agropecuários" (OLIVEIRA, 1997, p. 290).

Esta intervenção do governo foi realizada, principalmente, através do Prodoeste (Programa de Desenvolvimento do CentroOeste), efetivado pela ação da Sudam (Superintendência do Desenvolvimento da Amazônia), no qual muitos grupos empresariais beneficiaram-se em diversos aspectos do processo de ocupação da fronteira amazônica. Vale lembrar que vários projetos aprovados, alguns megalomaníacos, nunca efetivamente entraram em funcionamento, o que gerou uma série de escândalos pelo uso indevido de dinheiro público. Os autores ainda sugerem que a década de 70 foi fundamental para compreender a estrutura produtiva e a urbanização do Centro-Oeste, já que a região foi amplamente beneficiada pela "marcha modernizadora do oeste", provocando um intenso direcionamento dos fluxos migratórios para áreas mais promissoras.

Posteriormente, ocorreu uma articulação entre Estado e detentores de representativos volumes de capital, realizando incentivos para que estes pequenos produtores se engajassem em projetos de colonização, característicos da década de 80 , em substituição aos grandes projetos agropecuários da de 70. Diante disto, pode-se observar que os anos 80 caracterizaram-se pela realização destes projetos de colonização, baseados em assentamentos de famílias em pequenas propriedades e executados por empresas públicas e privadas. Porém, estes projetos acabaram limitados e tiveram suas chances de sucesso reduzidas por diversos elementos, tais como: características qualitativas da terra; dificuldade de acesso ao crédito por parte dos pequenos agricultores; e condições de isolamento da maioria das áreas colonizadas (em particular no caso do norte de Mato Grosso). Neste contexto, a abertura dos grandes eixos rodoviários, especialmente a BR-163 Cuiabá-Santarém (1971-1976), foi um marco representativo da efetiva implantação dos projetos de colonização.

Como conseqüência desta "colonização acelerada", ocorreu a multiplicação de diversos novos municípios nas áreas de fronteira, como é o caso do norte de Mato Grosso, os quais sofrem até hoje com a ausência de infra-estrutura e serviços. São cidades pequenas, na maioria das vezes com população variando entre 20 e 50 mil habitantes, distantes geograficamente umas das outras.

Diante desta forma de ocupação populacional, surgiu um novo tipo de atividade agrícola, isto é, a agricultura altamente capitalizada e mecanizada, cuja forma mais difundida em Mato Grosso é a cultura da soja. Segundo Becker (2000), a soja chega a ser uma opção viável nos cerrados ou para recuperar áreas com pastagens, principalmente quando se considera a melhoria genética das sementes, conseguida através de pesquisas financiadas pela iniciativa privada com apoio estatal, apresentando assim efeitos positivos. No entanto, a autora teme pelo aumento do desmatamento que esta cultura pode gerar se avançar muito ao norte do Estado, aumentando, portanto, a tendência à destruição do meio ambiente.

Outra atividade econômica importante nestas áreas de fronteira é a pecuária, que vem penetrando cada vez mais nas áreas florestais. Este aspecto é ressaltado por Cláudio Egler (2000), que mostra como o capital financeiro tem investido na constituição de uma forte economia agropastoril no Estado de Mato Grosso (o 4 o rebanho nacional). Além disso, existem ainda outros aspectos que devem ser considerados quando se pretende compreender o processo de ocupação de Mato Grosso: a questão indígena, o meio ambiente e a prática do garimpo. 
Embora tais questões não sejam tratadas neste artigo, não se pode negar a existência, no Estado, de diversos problemas inerentes a elas, como, por exemplo, o desrespeito às terras indígenas, a devastação ambiental e o efeito predatório dos garimpos. Estes aspectos constituem elementos importantes que estão relacionados ao processo de ocupação e expansão da fronteira agrícola no Estado do Mato Grosso.

Estas características do processo de ocupação territorial, aliadas à expansão do modelo agrário convencional, foram extremamente prejudiciais para o produtor familiar e causaram ainda fortes impactos socioambientais, como mostram os dados do Inpe (Instituto Nacional de Pesquisas Espaciais): até agosto de 1998, 10\% das florestas já estavam desmatadas. Provavelmente a demanda por madeira é a grande responsável por essa situação crítica, já que Mato Grosso e Pará são os maiores produtores de madeira em tora do país. Além disso, depois da realização das queimadas, a pecuária acaba sendo a alternativa mais imediata para a valorização da terra.

Este cenário acaba gerando grandes focos de "tensão social" em territórios ma- togrossenses. Todas estas características tiveram forte impacto no processo migratório experimentado pelo Estado de Mato Grosso, sendo que tais elementos exprimem-se tanto em termos das tendências do fenômeno ao longo do tempo, como no que tange ao perfil desta mobilidade populacional.

\section{A dinâmica demográfica em nível regional}

Os dados sobre o crescimento populacional e o processo de urbanização de Mato Grosso não deixam dúvida quanto ao fato de que, nos anos 90 (mais precisamente no segundo qüinqüênio da década de $80^{2}$ ), o Estado passou por uma importante inflexão no seu crescimento demográfico, resultante das significativas transformações no seu processo de desenvolvimento econômico e estrutura produtiva, entre outros fatores (Tabela 1).

O crescimento demográfico no Estado, que durante vários períodos registrou altas taxas - superior a $5 \%$ ao ano nas décadas de 70 e parte da de 80 -, reduziu-se abruptamente nos anos 90 , atingindo cerca de $2,4 \%$ a.a., embora ainda tenha sido bem superior à média nacional $\mathrm{e}$ ao desempenho

TABELA 1

População total, taxa de crescimento médio e grau de urbanização Região Centro-Oeste Ampliada - 1970-2000

\begin{tabular}{|c|c|c|c|c|c|c|c|c|c|c|c|}
\hline \multirow[t]{2}{*}{ Estados } & \multicolumn{4}{|c|}{ População } & \multicolumn{3}{|c|}{$\begin{array}{c}\text { Taxa de crescimento } \\
\text { (\% a.a.) }\end{array}$} & \multicolumn{4}{|c|}{$\begin{array}{c}\text { Grau de urbanização } \\
(\%)\end{array}$} \\
\hline & 1970 & 1980 & 1991 & 2000 & $1970 / 80$ & 1980/91 & $11991 / 2000$ & 1970 & 1980 & 1991 & 2000 \\
\hline Distrito Federal & 537.492 & 1.176 .935 & 1.598 .415 & 2.043 .169 & 8,15 & 2,82 & 2,77 & 96 & 96,8 & 94,7 & 95,7 \\
\hline Goiás & 2.414 .325 & 3.125 .354 & 4.012 .562 & 4.994 .897 & 2,61 & 2,3 & 2,46 & 45,9 & 67,5 & 80,8 & 87,9 \\
\hline Mato Grosso & 598.879 & 1.134 .230 & 2.022 .524 & 2.498 .150 & 6,59 & 5,4 & 2,37 & 38,8 & 57,7 & 73,3 & 79,4 \\
\hline $\begin{array}{l}\text { Mato Grosso } \\
\text { do Sul }\end{array}$ & 998.211 & 1.393 .019 & 1.778 .741 & 2.075 .275 & 3,39 & 2,25 & 1,73 & 45,3 & 66,8 & 79,4 & 84,1 \\
\hline Rondônia & 111.064 & 491.069 & 1.130 .874 & 1.377 .792 & 16,03 & 7,88 & 2,22 & 53,6 & 46,5 & 58,2 & 64,1 \\
\hline Tocantins & 516.447 & 743.750 & 920.116 & 1.155 .251 & 3,71 & 1,95 & 2,56 & 24,8 & 40,1 & 57,7 & 74,3 \\
\hline Total & 5.176 .418 & 8.064 .357 & 11.463.232 & 14.144 .534 & 4,53 & 3,25 & 2,36 & 48,2 & 66,5 & 77,1 & 83,5 \\
\hline
\end{tabular}

Fonte: IBGE. Censos Demográficos 1970, 1980, 1991 e 2000. Tabulações especiais Nepo/Unicamp.

\footnotetext{
${ }^{2}$ Em estudo anterior pôde-se mostrar que os dados analisados levavam a crer que, de fato, a inflexão do processo de ocupação matogrossense parece ter mesmo ocorrido a partir de meados dos anos 80 . Vale lembrar que neste mesmo período houve a interrupção dos incentivos governamentais fartamente oferecidos para projetos de colonização e expansão da fronteira agrícola (MARTINE, 1994). Para maiores detalhes sobre estas tendências, ver Cunha $(2001,2002)$ e Cunha e Silveira (1999).
} 
de outros Estados do Centro-Oeste, em particular do Mato Grosso do Sul (Tabela 1).

Ao mesmo tempo em que ocorria redução do crescimento demográfico, Mato Grosso também se urbanizava a passos largos. Segundo o Censo de 2000, nada menos que $80 \%$ de sua população vivia nas cidades; uma taxa alta mesmo considerando-se que o grau de urbanização do território matogrossense possa estar superestimado, devido à forma como a informação é captada pelo IBGE, que, como argumenta Veiga (2002), tende a considerar "cidades" espaços claramente sem as condições mínimas para tal. Vale lembrar, para efeitos deste estudo, que somente cerca de $20 \%$ da população de Mato Grosso ainda residia realmente nas zonas rurais.

Para um Estado que foi ocupado e colonizado com base em programas de assentamentos rurais, não é difícil perceber que existe uma aparente contradição: possui uma estrutura econômica nitidamente baseada na agropecuária, mas com pouquíssima população residindo nas zonas rurais, o que reflete as conseqüências do estilo de desenvolvimento adotado.

Assim, Mato Grosso caracteriza-se não apenas pela predominância de grandes latifúndios, mas também por uma produção primária baseada na monocultura e/ou pecuária extensiva. No primeiro caso, a produção agrícola é altamente tecnificada e, portanto, utiliza pouca mão-de-obra na realização destas atividades. Os dados apresentados a seguir demonstram vários aspectos evidenciados neste processo peculiar de desenvolvimento.

Tal redução das intensidades do crescimento demográfico espelha, em grande medida, o arrefecimento da migração. De fato, os dados censitários mostram que a imigração proveniente de outros Estados reduziu-se em quase $23 \%$ entre as décadas de 80 e 90 , embora ainda tenha atingido volumes superiores aos fluxos referentes aos anos $70 .^{3}$ Contudo, o impacto destes fluxos migratórios sobre a população do Estado claramente vem perdendo força, uma vez que esta taxa diminuiu de $0,94 \%$ a.a. no primeiro período analisado para $0,58 \%$ a.a. nos anos 90 , ou seja, para quase a metade do que ocorria há 20 anos.

Em termos dos fluxos migratórios mais significativos, a Tabela 2 mostra que, aliada à redução da imigração, ocorreu uma mudança significativa no perfil dos movimentos quanto à última residência dos migrantes. Enquanto no auge da ocupação as pessoas provenientes do Paraná representavam cerca de $35 \%$, respondendo, juntamente com outras origens como Goiás (14\%), São Paulo (13\%) e Mato Grosso do Sul (11\%), por quase 3/4 da imigração registrada, nos anos 90 o quadro modifica-se bastante. Percebe-se uma brusca redução na participação relativa do Paraná (19\%), o que acaba permitindo um aumento naquela de outras origens, como é o caso de Rondônia.

No entanto, em algumas áreas, como na microrregião de Colíder, os nordestinos ocupam também lugar de destaque nos anos 80 , seduzidos principalmente pelo enriquecimento fácil que o garimpo prometia. Justamente foi essa microrregião a que recebeu maior volume de imigração entre as três áreas do norte de Mato Grosso. Esta situação mostra as diferenças existentes entre os vários tipos de migração destinados para o Estado, sendo, em geral, distintas as motivações e principalmente a natureza destes movimentos caso se trate de nordestinos ou de sulistas. ${ }^{4}$

$\mathrm{O}$ arrefecimento de imigração, relacionado à indiscutível diminuição dos atrativos

\footnotetext{
${ }^{3}$ Cabe uma explicação de caráter metodológico. Os Censos de 1991 e 2000 permitem que se capte, em âmbito estadual, o migrante tanto em termos de sua "última residência" (última etapa), quanto com relação à sua "residência 5 anos antes" (data fixa) do recenseamento. Porém, no Censo de 80, a informação sobre "data fixa" não é recolhida. Embora cada um dos tipos de "definição" de migrante tenha suas vantagens e desvantagens (CARVALHO e MACHADO, 1992), existe por parte deste estudo uma preferência pela "última etapa", por refletir os movimentos mais recentemente ocorridos e permitir uma maior abrangência temporal. Assim, os volumes derivados de ambas as formas de identificação dos migrantes, além de intervalos de tempo diferentes, são também de naturezas distintas, sendo comparáveis apenas em situações particulares que não vêm ao caso explicitar neste momento.

${ }^{4}$ Para uma discussão sobre as diferenças da migração de nordestinos e sulistas, ver Cunha e Azevedo (2001)
} 
TABELA2

Imigrantes e emigrantes com menos de 10 anos de residência nos Estados de domicílio atual Estado de Mato Grosso - 1980-2000

\begin{tabular}{|c|c|c|c|c|c|c|c|c|}
\hline \multirow{2}{*}{$\begin{array}{l}\text { Principais } \\
\text { Fluxos }\end{array}$} & \multicolumn{2}{|c|}{1980} & \multicolumn{2}{|c|}{1991} & \multicolumn{2}{|c|}{2000} & \multicolumn{2}{|c|}{$\begin{array}{c}\text { Variação (\%) } \\
1980 / 20000\end{array}$} \\
\hline & Imigrantes & Emigrantes & Imigrantes & Emigrantes & Imigrantes(1) & Emigrantes & Imigrantes & Emigrantes \\
\hline Paraná & 112.440 & 4.529 & 164.597 & 52.559 & 76.516 & 39.839 & $-31,9$ & 779,6 \\
\hline Goiás (2) & 46.706 & 16.027 & 51.121 & 29.528 & 55.976 & 42.747 & 19,8 & 166,7 \\
\hline São Paulo & 41.833 & 20.176 & 64.120 & 37.689 & 46.387 & 45.425 & 10,9 & 125,1 \\
\hline $\begin{array}{l}\text { Mato Grosso } \\
\text { do Sul }\end{array}$ & 35.297 & 13.091 & 68.320 & 24.828 & 52.777 & 26.561 & 49,5 & 102,9 \\
\hline Minas Gerais & 31.708 & 6.289 & 24.267 & 12.120 & 18.358 & 9.331 & $-42,1$ & 48,4 \\
\hline Rondônia & 3.692 & 47.455 & 30.509 & 39.531 & 46.194 & 26.766 & 1151,3 & $-43,6$ \\
\hline Bahia & 7.831 & 1.182 & 12.262 & 2.595 & 10.192 & 3.584 & 30,1 & 203,3 \\
\hline $\begin{array}{l}\text { Rio Grande } \\
\text { do Sul }\end{array}$ & 17.893 & 1.047 & 27.800 & 8.738 & 20.610 & 8.103 & 15,2 & 673,6 \\
\hline Santa Catarina & 7.703 & 597 & 25.880 & 6.320 & 17.193 & 8.415 & 123,2 & 1310,2 \\
\hline Pará & 2.006 & 2.451 & 13.210 & 7.970 & 14.289 & 11.897 & 612,2 & 385,5 \\
\hline Maranhão & 1.463 & 376 & 22.148 & 2.504 & 13.525 & 4.014 & 824,7 & 967,8 \\
\hline Distrito Federal & 1.765 & 2.310 & 4.923 & 2.744 & 3.598 & 4.534 & 103,8 & 96,3 \\
\hline Outros & 18.040 & 6.204 & 34.022 & 17.312 & 44.682 & 18.207 & 147,7 & 193,5 \\
\hline Total MT & 328.376 & 121.731 & 543.179 & 244.438 & 420.296 & 249.423 & 28,0 & 104,9 \\
\hline
\end{tabular}

Fonte: IBGE. Censos Demográficos 1970, 1980, 1991 e 2000. Tabulações especiais Nepo/Unicamp.

(1) Este volume considera a distribuição "pro-rata" feita para os migrantes sem declaração de UF de residência anterior

(2) Para efeito da manutenção da comparabilidade para 1991 e 2000, os volumes de Goiás foram somados aos de Tocantins.

para os migrantes, especialmente para aqueles interessados na "promessa" das fronteiras agrícolas para se estabelecerem como pequenos proprietários e desenvolverem uma agricultura ou pecuária em base familiar, não foi o único fator demográfico responsável pela redução do crescimento populacional matogrossense. Houve também intensificação da emigração para fora de Mato Grosso, a partir dos anos 80, registrando inclusive aumento absoluto na década de 90 da ordem de $100 \%$ se comparada à de 70 .

De qualquer modo, é importante notar que a emigração praticamente estabilizouse entre os anos 80 e 90 e, como conseqüência, sofreu uma redução de sua intensidade $(0,39 \%$ a.a. e $0,34 \%$ a.a., respectivamente). Esta certa estabilização das perdas populacionais evidencia, por um lado, que o maior impacto das grandes transformações produtivas no Estado parece já ter ocorrido entre meados dos anos 80 e começo dos 90 e, por outro, a redução significativa de imigração já de- monstrada anteriormente. De fato, à medida que passam a ingressar menos migrantes no Estado, seria natural esperar uma redução também do volume de saídas.

Além disso, outro elemento deve ser considerado ao se analisar a emigração de Mato Grosso: o retorno de muitos dos migrantes para suas zonas de origem, em particular durante a década de 90 . Como se nota no Gráfico 1, do total daqueles que deixaram o Estado, mais de $54 \%$ retornaram para suas Unidades da Federação de nascimento, valor bem superior àquele observado na década anterior (pouco mais de $21 \%$ ).

Tal fato permite considerar que esta emigração configura-se, na verdade, como um processo não de expulsão destes migrantes de Mato Grosso, mas sim de retorno à origem, decorrente da constatação das dificuldades de fixação e/ou insucessos, favorecidos pela interação de diversos elementos, tais como: inexistência de terras adequadas em função do alto grau de concentração fundiária; políticas pouco 
GRÁFICO 1

Emigrantes, por condição de naturalidade, segundo região de destino Estado de Mato Grosso - 1991-2000

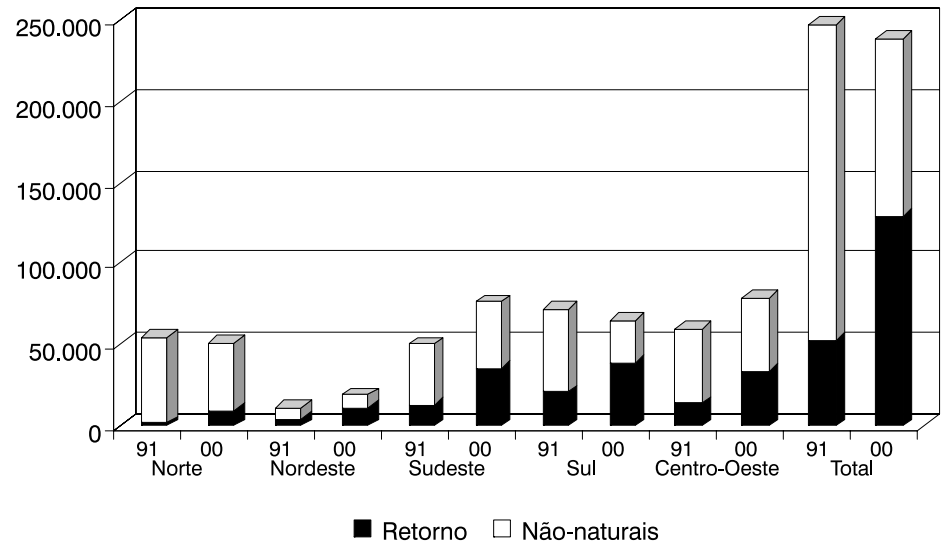

Fonte: IBGE. Censos Demográficos 1991 e 2000. Tabulações especiais Nepo/Unicamp.

eficazes de assentamentos; falta de alternativas produtivas que permitissem a reprodução social; etc.

No entanto, percebe-se que, nos anos 80 , a baixa taxa de retorno atingia não apenas os sulistas, que tradicionalmente quase não retornam (CUNHA e AZEVEDO, 2001 e CUNHA, 2004), mas todos os demais migrantes, independentemente da procedência, inclusive os próprios nordestinos. Este fato conduz à avaliação da hipótese de que, naquele período, a abertura de outras fronteiras ainda era uma realidade, o que permitia aos migrantes a busca de outras possibilidades antes da volta para os Estados de origem. Esta hipótese é fortalecida quando se observa que, nos anos 90 , até mesmo os sulistas apresentaram volume e proporção significativos de migrantes retornados.

As características migratórias de Mato Grosso podem ser mais bem percebidas e interpretadas a partir da desagregação da análise em termos regionais, ${ }^{5}$ tendo em vista a heterogeneidade do território estadual, no que diz respeito tanto ao comportamento demográfico quanto às especificidades do processo de ocupação (aí incluindo os diferentes momentos históricos: transformações econômicas, estrutura fundiária, uso, ocupação, cobertura do solo, etc.).

Até a década de 80 , o Estado poderia ser dividido, grosso modo, em duas porções: o norte, compondo uma área de maior dinamismo demográfico nas duas últimas décadas; e o sul, formando uma área mais consolidada e com menores taxas de incremento demográfico. De fato, enquanto localidades no extremo norte, como Alta Floresta, Colíder e Alto Teles Pires, cresceram a taxas elevadíssimas nos anos 80 , nas regiões mais ao sul isso não ocorreu, com exceção de Cuiabá e Rondonópolis, que, mesmo nos anos 90, apresentavam algum "fôlego", crescendo a taxas superiores a $2 \%$ ao ano. Na verdade, nestes dois casos, trata-se de microrregiões onde localizam-se importantes centros urbanos as principais cidades do Estado -, que contam com maior diversificação econômica,

${ }^{5}$ Dada a falta de comparabilidade entre os Censos no que se refere às informações sobre migração intermunicipal, para a análise da dinâmica intra-estadual utilizou-se a informação referente à residência cinco anos antes, para os Censos 1991 e 2000, e última residência para os migrantes maiores de cinco anos de idade e com menos de cinco anos de residência, para o Censo de 1980. 
TABELA 3

População e taxa de crescimento demográfico, segundo microrregiões

Estado de Mato Grosso - 1970-2000

\begin{tabular}{|c|c|c|c|c|c|c|c|}
\hline \multirow{2}{*}{ Microrregiões } & \multicolumn{4}{|c|}{ População total } & \multicolumn{3}{|c|}{ Taxa de crescimento ( $\%$ a.a.) } \\
\hline & 1.970 & 1.980 & 1.991 & 2.000 & $1970 / 1980$ & $1980 / 1991$ & $1991 / 2000$ \\
\hline Alta Floresta & 1.287 & 23.011 & 86.229 & 89.848 & 33,4 & 12,8 & 0,5 \\
\hline Alto Araguaia & 13.437 & 17.888 & 22.007 & 24.117 & 2,9 & 1,9 & 1,0 \\
\hline Alto Guaporé & 8.095 & 19.738 & 48.250 & 60.663 & 9,3 & 8,5 & 2,6 \\
\hline Alto Pantanal & 75.186 & 82.941 & 117.037 & 123.141 & 1,0 & 3,2 & 0,6 \\
\hline Alto Paraguai & 25.187 & 34.624 & 43.407 & 30.512 & 3,2 & 2,1 & $-3,8$ \\
\hline Alto Teles Pires & 7.028 & 19.069 & 50.643 & 101.610 & 10,5 & 9,3 & 8,0 \\
\hline Arinos & 2.911 & 22.281 & 48.842 & 67.447 & 22,6 & 7,4 & 3,7 \\
\hline Aripuanã & 1.405 & 15.888 & 70.949 & 96.989 & 27,5 & 14,6 & 3,5 \\
\hline Canarana & 12.099 & 34.476 & 65.904 & 79.086 & 11,0 & 6,1 & 2,0 \\
\hline Colíder & 1.702 & 26.004 & 138.683 & 129.325 & 31,3 & 16,4 & $-0,8$ \\
\hline Cuiabá & 145.046 & 314.045 & 601.449 & 740.648 & 8,0 & 6,1 & 2,3 \\
\hline Jauru & 39.064 & 107.145 & 112.083 & 106.358 & 10,6 & 0,4 & $-0,6$ \\
\hline Médio Araguaia & 11.183 & 43.607 & 54.371 & 61.073 & 14,6 & 2,0 & 1,3 \\
\hline Norte Araguaia & 10.094 & 27.602 & 57.535 & 87.251 & 10,6 & 6,9 & 4,7 \\
\hline Paranatinga & 7.840 & 23.273 & 27.924 & 28.591 & 11,5 & 1,7 & 0,3 \\
\hline Parecis & 3.055 & 10.235 & 32.156 & 61.771 & 12,9 & 11,0 & 7,5 \\
\hline Primavera do Leste & 10.956 & 12.839 & 18.507 & 56.959 & 1,6 & 3,4 & 13,3 \\
\hline Rondonópolis & 114.222 & 139.663 & 187.068 & 223.741 & 2,0 & 2,7 & 2,0 \\
\hline Rosário do Oeste & 26.898 & 28.374 & 30.563 & 31.347 & 0,5 & 0,7 & 0,3 \\
\hline Sinop & 3.658 & 23.959 & 74.186 & 131.445 & 20,7 & 10,8 & 6,6 \\
\hline Tangará da Serra & 24.840 & 54.940 & 73.854 & 112.086 & 8,3 & 2,7 & 4,7 \\
\hline Tesouro & 53.686 & 52.628 & 60.877 & 54.142 & $-0,2$ & 1,3 & $-1,3$ \\
\hline Total & 598.879 & 1.134 .230 & 2.022 .524 & 2.498 .150 & 6,6 & 5,4 & 2,4 \\
\hline
\end{tabular}

Fonte: IBGE. Censos Demográficos de 1970, 1980, 1991 e 2000. Tabulações especiais Nepo/Unicamp.

sem considerar o fato de a primeira concentrar praticamente todo o aparato administrativo estadual como capital de Mato Grosso (Tabela 3).

Já nos anos 90, observam-se até três situações diferentes: maior urbanização e dinamismo nas microrregiões de Cuiabá, Rondonópolis e Alto Pantanal, onde as atividades industriais e o setor de serviços são bastante desenvolvidos; um processo de ocupação um tanto diferente na região central do Estado - a maior parte do Cerrado -, abarcando as microrregiões de Parecis, Primavera do Leste, Alto Teles Pires e Canarana, com presença muito forte da soja - o principal produto agrícola -, aliada à cultura do algodão e do milho; e intenso ritmo de crescimento demográfico no norte do Estado (ou "nortão", como é conhecido), até o final da década de 80 , devido à expansão da fronteira agrícola e, principalmente, à atividade garimpeira, em clara queda nos anos 90 .

No chamado "nortão" do Estado, enquanto as regiões mais ao norte, como Alta Floresta e Colíder, reduziram drasticamente seu crescimento, na década de 90 , outras áreas da porção ocidental, como Parecis, Alto Guaporé, Alto Teles Pires e Aripuanã, ainda que em menor ritmo, mantiveram significativo dinamismo demográfico (Mapa 1). O mesmo pode-se dizer de áreas no nordeste do Estado, em particular a microrregião do Norte Araguaia. Enquanto em Alta Floresta e Colíder a quase erradicação da atividade garimpeira explicaria boa parte do processo, nas outras áreas novos projetos de assentamentos (em particular em Aripuanã, ao noroeste, e Norte Araguaia, no nordeste) e, principalmente, a 


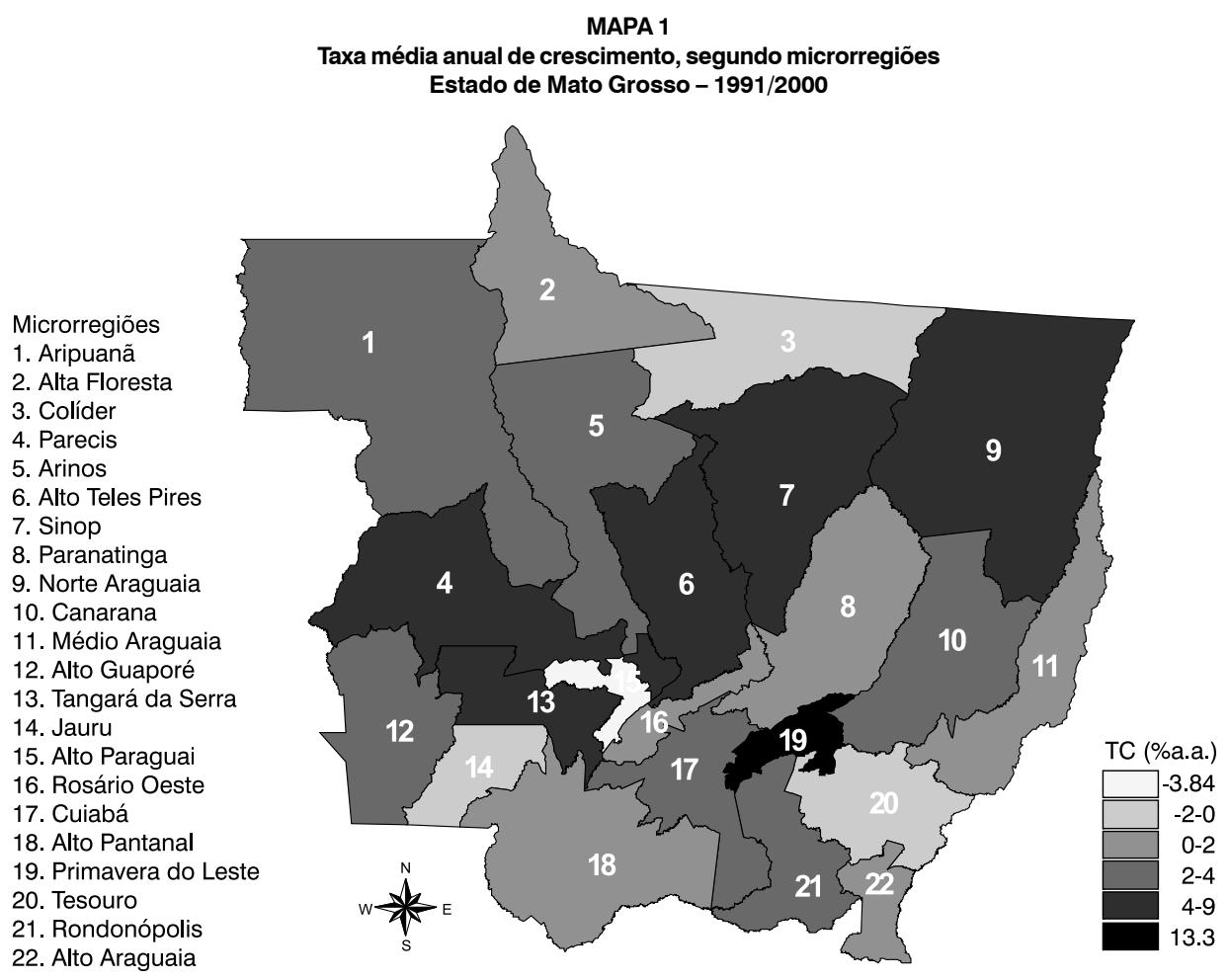

Fonte: IBGE. Censos Demográficos 1991 e 2000. Tabulações especiais Nepo/Unicamp.

entrada da soja (nas demais regiões) poderiam ser os elementos que justificariam tal comportamento.

De fato, como mostra a Tabela 4, várias regiões mencionadas anteriormente figuram entre aquelas que mais receberam este tipo de projeto, inclusive em termos do número de famílias envolvidas, ${ }^{6}$ como são os casos das microrregiões Norte Araguaia e Aripuanã.

Em termos de volumes migratórios apresentados por cada uma das microrregiões de Mato Grosso, a Tabela 5 explicita as situações e momentos distintos pelos quais passaram estas áreas ao longo do período estudado. Enquanto as localidades mais urbanizadas e dinâmicas do Estado reduziram o volume de imigração interestadual, outras, como as do norte e noroeste do Estado, bem como aquelas com influência mais recente da soja, registraram incremento do contingente de pessoas que lá chegaram.

Embora o Mato Grosso tenha se urbanizado em ritmo bastante intenso nas últimas décadas, particularmente em função das grandes transformações pelas quais passaram as suas áreas rurais, a migração com destino a estes locais ainda é significativa em várias regiões.

Por um lado, observa-se que, para o total do Estado, a migração com destino rural reduziu-se tanto em volume (de 128 mil em 1986/91, para 51,8 mil em 1995/00) quanto em porcentual (de $55 \%$ para menos de $21 \%^{7}$ ). Por outro lado, microrregiões como Norte Araguaia, Alto Guaporé e Rosário do Oeste, ainda nos anos 90 , apresentaram $40 \%$ dos

\footnotetext{
${ }^{6}$ Deve-se considerar que os projetos de assentamentos são bastante heterogêneos em termos das áreas e número de famílias envolvidas.

${ }^{7}$ Claro que o total do Estado está influenciado pelo peso de Cuiabá e Rondonópolis, onde se concentra boa parte dos migrantes que são, desde os anos 70, predominantemente de destino urbano (ver Tabela 5)
} 
TABELA4

Distribuição dos assentamentos rurais, segundo microrregiões Estado de Mato Grosso - 1991/2000

\begin{tabular}{lcc}
\hline Microrregióes & $\begin{array}{c}\text { Número de } \\
\text { Assentamentos }\end{array}$ & $\%$ \\
\hline Alta Floresta & 5 & 1,9 \\
Alto Araguaia & 1 & 0,4 \\
Alto Guaporé & 13 & 5,0 \\
Alto Pantanal & 15 & 5,7 \\
Alto Paraguai & 6 & 2,3 \\
Alto Teles Pires & 10 & 3,8 \\
Arinos & 15 & 5,7 \\
Aripuanã & 17 & 6,5 \\
Canarana & 13 & 5,0 \\
Colíder & 23 & 8,8 \\
Cuiabá & 11 & 4,2 \\
Jauru & 7 & 2,7 \\
Médio Araguaia & 2 & 0,8 \\
Norte Araguaia & 37 & 14,1 \\
Paranatinga & 5 & 1,9 \\
Parecis & 11 & 4,2 \\
Primavera do Leste & 5 & 1,9 \\
Rondonópolis & 18 & 6,9 \\
Rosário do Oeste & 12 & 4,6 \\
Sinop & 14 & 5,3 \\
Tangará da Serra & 7 & 2,7 \\
Tesouro & 15 & 5,7 \\
Total & 262 & 100,0 \\
\hline
\end{tabular}

Fonte: Incra - MT, Superintendência Regional de Mato Grosso - SR-13/MT. Tabulações especias Nepo/Unicamp.

Nota: Incluem-se os municípios com projetos administrados pelo Intermat e municípios com "projetos casulo" de assentamentos.

TABELA 5

Imigração interestadual de última etapa, segundo microrregiões

Estado de Mato Grosso - 1970-2000

\begin{tabular}{lccc}
\hline Microrregiões & & Volumes interestaduais & $\mathbf{1 9 9 1 / 2 0 0 0}$ \\
\hline Alta Floresta & $\mathbf{1 9 7 0 / 1 9 8 0}$ & $\mathbf{1 9 8 0 / 1 9 9 1}$ & 15.061 \\
Alto Araguaia & 9.729 & 46.226 & 4.034 \\
Alto Guaporé & 20.679 & 5.060 & 11.056 \\
Alto Pantanal & 30.793 & 14.133 & 8.249 \\
Alto Paraguai & 6.428 & 10.695 & 2.230 \\
Alto Teles Pires & 16.527 & 4.181 & 35.361 \\
Arinos & 4.616 & 25.671 & 12.139 \\
Aripuanã & 17.567 & 18.411 & 30.090 \\
Canarana & 6.153 & 36.407 & 16.379 \\
Colíder & 7.669 & 20.879 & 23.304 \\
Cuiabá & 16.735 & 72.161 & 83.149 \\
Jauru & 14.483 & 112.783 & 9.926 \\
Médio Araguaia & 7.817 & 20.321 & 10.106 \\
Norte Araguaia & 23.902 & 12.186 & 23.669 \\
Paranatinga & 35.858 & 18.286 & 3.490 \\
Parecis & 7.547 & 5.640 & 20.752 \\
Primavera do Leste & 977 & 13.627 & 17.505 \\
Rondonópolis & - & 9.887 & 29.986 \\
Rosário Oeste & 50.490 & 34.136 & 1.445 \\
Sinop & 8.139 & 1.721 & 34.979 \\
Tangará da Serra & 7.414 & 37.734 & 22.411 \\
Tesouro & 30.647 & 18.724 & 4.973 \\
Total & 4.206 & 7.009 & $\mathbf{4 2 0 . 2 9 4}$ \\
\hline
\end{tabular}

Fonte: IBGE. Censos Demográficos 1970, 1980, 1991 e 2000. Tabulações especiais Nepo/Unicamp. 
TABELA 6

Migrantes interestaduais, por área de destino, segundo microrregiões Estado de Mato Grosso - 1970-2000

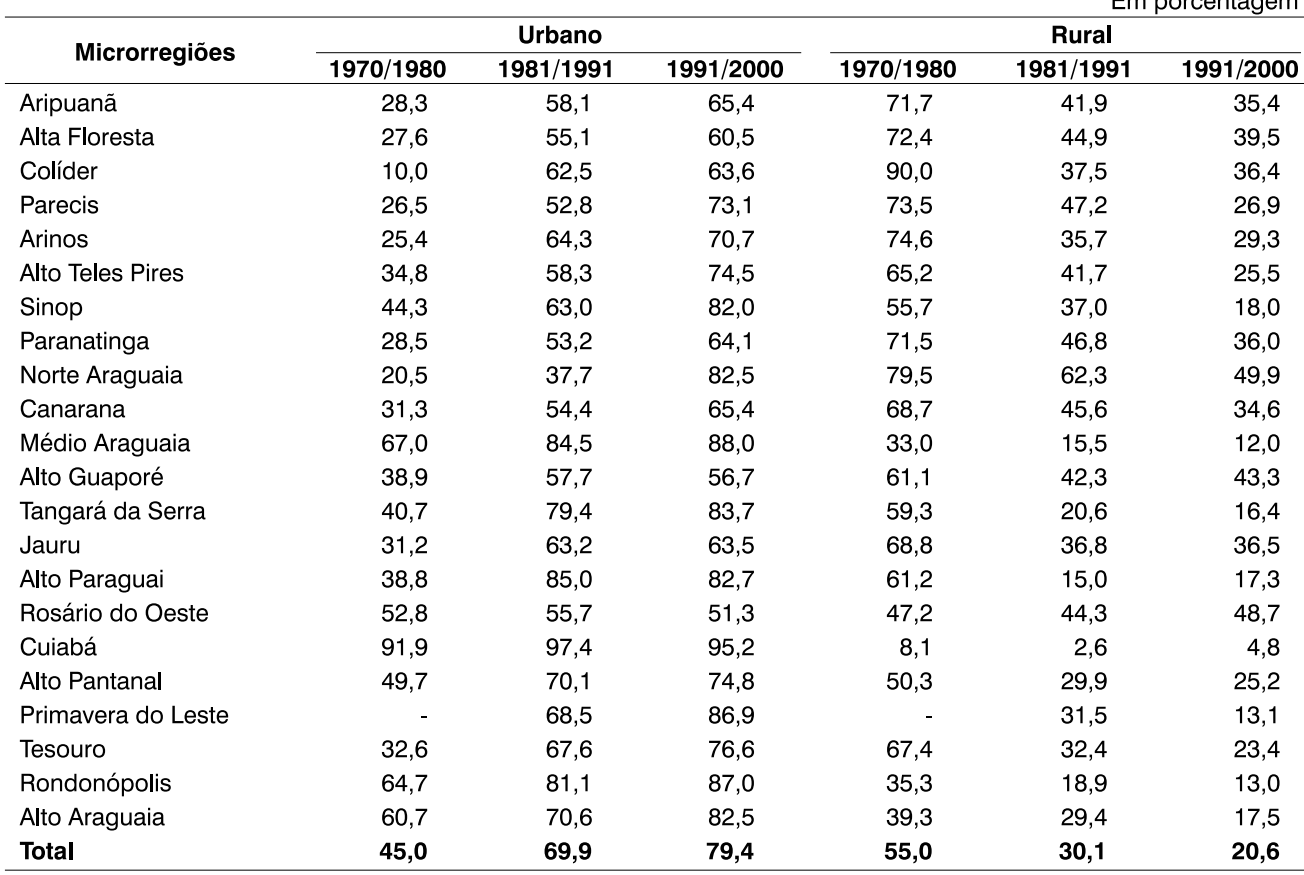

Fonte: IBGE. Censos Demográficos 1970, 1980, 1991 e 2000. Tabulações especiais Nepo/Unicamp.

migrantes se dirigindo para suas áreas rurais. Não menos significativos foram os porcentuais das micros do chamado "Nortão" - Aripuanã, Colíder e Alta Floresta -, que, no mesmo período, atingiram proporções em torno de $30 \%$ (Tabela 6).

É bem verdade que, na última década, na esteira dos custos sociais desse padrão de desenvolvimento, que repercutiram na concentração de terras e significativa redução do emprego agrícola (MATTEI, 1998), as políticas públicas nacionais voltaram-se um pouco mais para a questão da Reforma Agrária, que, não obstante suas várias deficiências, ${ }^{8}$ teve como conseqüência um aumento do número de assentamentos no país. Nota-se, por exemplo, o boom que o Estado de Mato Grosso teve neste período: segundo dados levantados junto ao Incra em Mato Grosso, ${ }^{9}$ enquanto no período 1986/91 foram criados em todo o Estado apenas 25 assentamentos, este número salta para 262 na década de 90 .

\section{As características da migração em Mato Grosso: os reflexos da forma de ocupação e as mudanças econômicas}

O principal intuito desta seção é demonstrar que as características dos migrantes mostram-se perfeitamente coerentes com a estrutura de condicionantes que este estudo identifica como fundamentais para justificar as tendências

\footnotetext{
${ }^{8}$ Foge do escopo deste trabalho discorrer sobre os vários problemas que cercam a Reforma Agrária no país e sua real eficácia para se configurar numa verdadeira saída para a população que ainda subsiste no campo. Alguns dos desafios encontrados referemse a: regularização das terras ocupadas; viabilização econômica dos assentamentos (o que envolve mecanismos de crédito); falta de assistência técnica e infra-estrutura, particularmente viária; terras desgastadas e de má qualidade para fins agrícolas, ou lotes em áreas de mata fechada; constrangimentos das leis ambientais; etc. É importante salientar que todos estes problemas foram reiteradamente levantados nas entrevistas realizadas nas várias regiões do Estado de Mato Grosso. Sobre estes temas ver Leite (1998), Gomes (2000), Ferreira, Fernández e Silva (s.d.).
} 
migratórias observadas no período em questão.

Além disso, enfatiza-se o fato de que tais migrantes apresentam certa seletividade que tende a se dissipar, à medida que o processo de ocupação da fronteira também vai se esvaindo ao longo do tempo. Em outras palavras, o perfil dos migrantes, ao mesmo tempo em que se transforma ao longo das décadas analisadas, também vai se "moldando" para uma realidade mais urbana, na proporção em que o destino rural torna-se cada vez menos predominante e inviável, em função da forma como o Estado se estrutura em termos econômicos e fundiários.

Quanto à dimensão demográfica, um dos primeiros elementos que merece destaque refere-se à composição etária, por sexo e familiar dos migrantes. Estudos como o de Sydenstricker (1992), para Machadinho em Rondônia, que tratam da ocupação da fronteira, observam que mesmo quando o chefe da família migrava previamente sozinho ou com os filhos homens mais velhos, visando preparar o lote, o caráter familiar desse tipo de deslocamento era incontestável. Os resultados de Diniz (2002) também mostram, para o caso de Roraima, que existe uma clara predominância de pessoas casadas, em particular nas fronteiras pioneiras. ${ }^{10}$

Na verdade, dada a especificidade dos "atrativos" da região para a migração como uma área de fronteira agrícola, em particular nas décadas passadas, seria de se supor que a migração tivesse um predomínio de famílias, ${ }^{11}$ a não ser em casos bem específicos, como regiões de garimpo, por exemplo.

Em termos demográficos, isso se refletiria, por um lado, na forma das pirâmides etárias e, por outro, no perfil da migração segundo os distintos tipos de arranjos domésticos, entre os quais aqueles relativos às "famílias nucleares", que acabariam por apresentar maior peso relativo. Nesse sentido, os dados apresentados a seguir mostram claramente esse comportamento. Como se percebe pelas distribuições etárias apresentadas (Gráficos 2, 3, 4), há claras evidências de que a migração interestadual do tipo familiar realmente predominou em Mato Grosso, em particular nos períodos em que o fenômeno foi mais intenso, como as década de 70 e 80 . Este fato se traduz na forma piramidal dos gráficos, muito embora fique claro que a participação de crianças menores de cinco anos de idade não é muito grande, guardando certa lógica com o que isso poderia implicar em termos dos constrangimentos para uma migração para áreas inóspitas, como são as regiões rurais de Mato Grosso.

De qualquer forma, é interessante notar que, já nos anos 90, o perfil etário dos migrantes sofreu significativa modificação, uma vez que se observa maior concentração de indivíduos nas idades produtivas, sugerindo, portanto, uma redução, ainda que pequena, da importância da migração do tipo familiar. Como se verá mais adiante, este fenômeno, de fato, foi verificado, o que aponta para uma mudança, ainda que lenta e gradativa, do perfil do migrante que se destina para Mato Grosso.

$\mathrm{Na}$ verdade, em 2000, quando a migração típica de "fronteira" certamente não tinha a mesma importância, a distribuição etária dos migrantes já mostrava uma maior seletividade com relação à população "nãomigrante" (Gráfico 5), ${ }^{12}$ em especial nas idades entre 20 e 35 anos. As observações suscitadas pelas pirâmides são plenamente corroboradas pela distribuição dos tipos das famílias de chefes migrantes interestaduais. Assim, a Tabela 7, ao mesmo tempo em que confirma a predominância de migração do tipo familiar para o Estado, também indica

\footnotetext{
${ }^{9}$ Incra - MT, Superintendência Regional de Mato Grosso - SR-13/MT.

${ }^{10} \mathrm{O}$ autor desenvolve uma tipologia muito interessante sobre "a trajetória evolutiva das fronteiras" (p.3), criando as categorias pioneira, transitória, consolidada e urbanizada. Muito embora tal classificação pudesse ser útil para a presente análise, os dados disponíveis não permitem esta diferenciação. Para maior detalhamento sobre a classificação, ver Diniz (2002 e 2003).

${ }^{11}$ Vale ressaltar mais uma vez que o Censo apenas capta o arranjo doméstico no momento da coleta da informação, o que, portanto, não assegura totalmente que este valia no momento da migração.

${ }^{12}$ Nesse estudo são considerados "não-migrantes" todos os indivíduos naturais de Mato Grosso que nunca migraram ou aqueles com mais de dez anos de residência no Estado.
} 
GRÁFICO 2

Pirâmide etária de imigrantes interestaduais, por sexo Estado de Mato Grosso - 1980

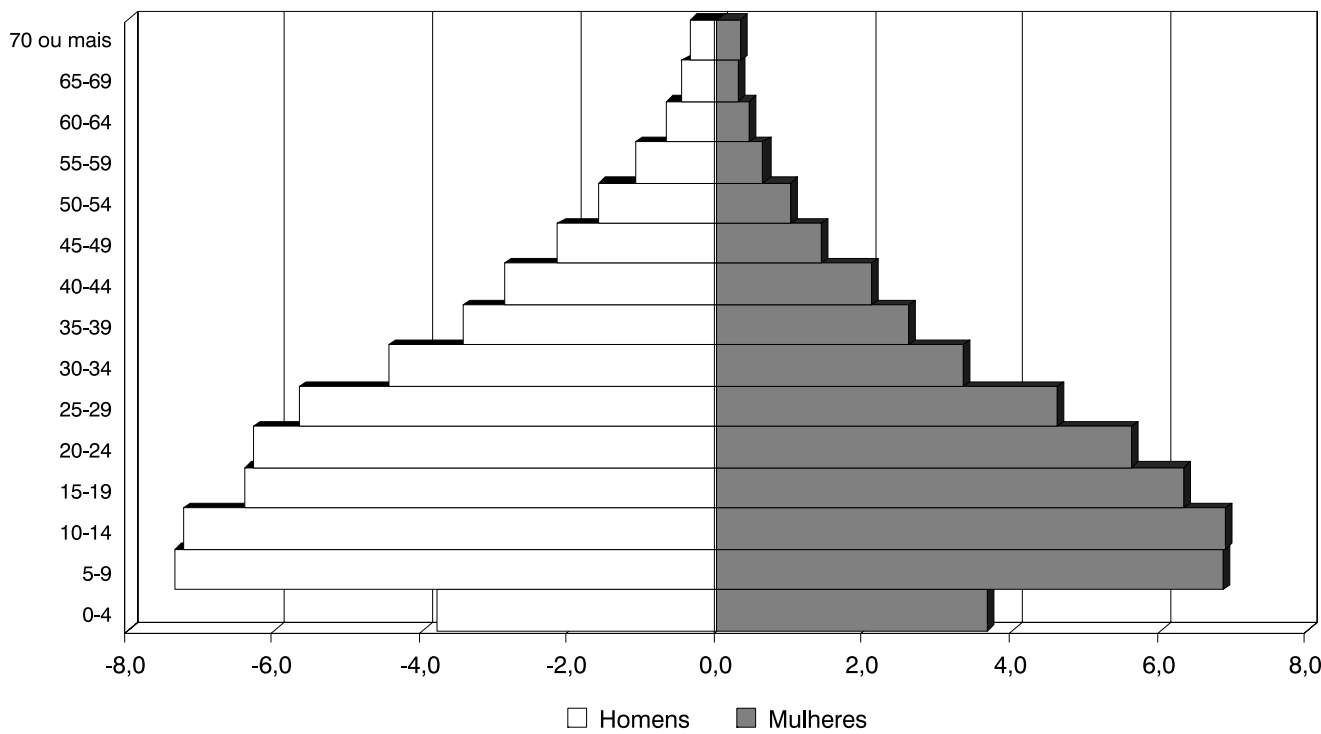

Fonte: IBGE. Censo Demográfico de 1980. Tabulações especiais Nepo/Unicamp.

GRÁFICO 3

Pirâmide etária de imigrantes interestaduais, por sexo

Estado de Mato Grosso - 1991

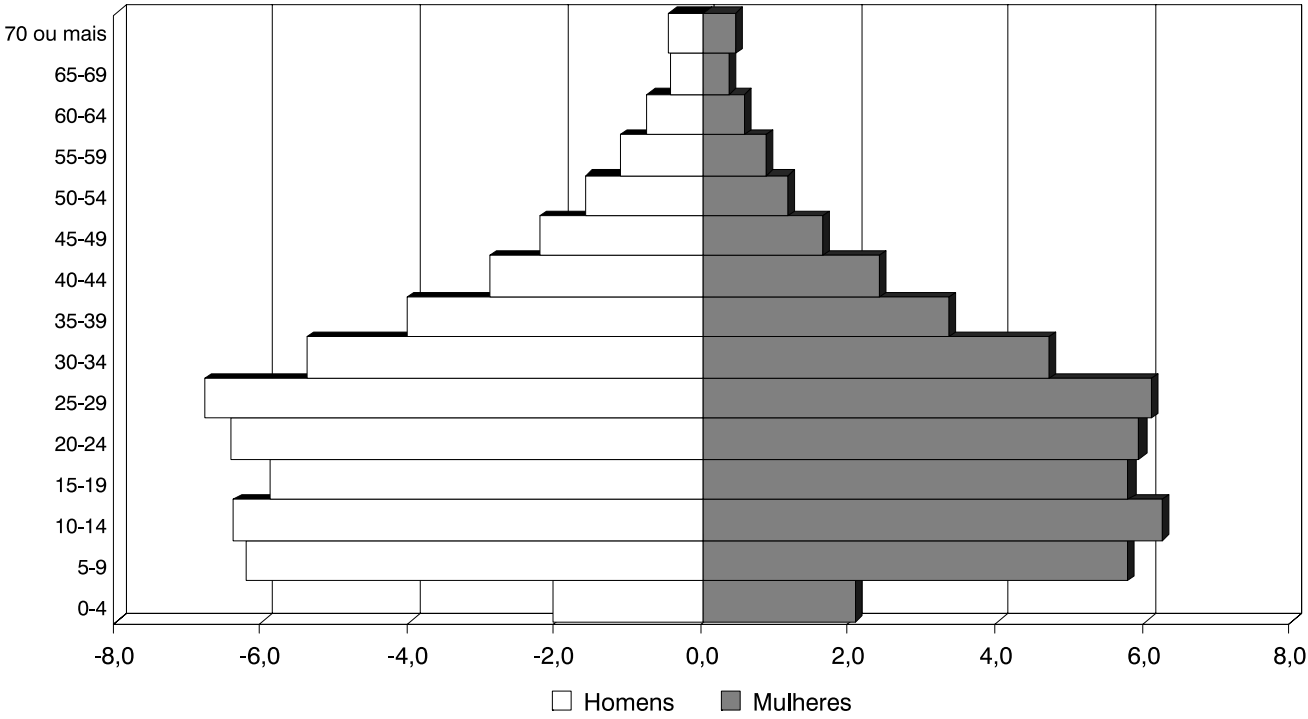

Fonte: IBGE. Censo Demográfico de 1991. Tabulações especiais Nepo/Unicamp. 
GRÁFICO 4

Pirâmide etária de imigrantes interestaduais, por sexo

Estado de Mato Grosso - 2000

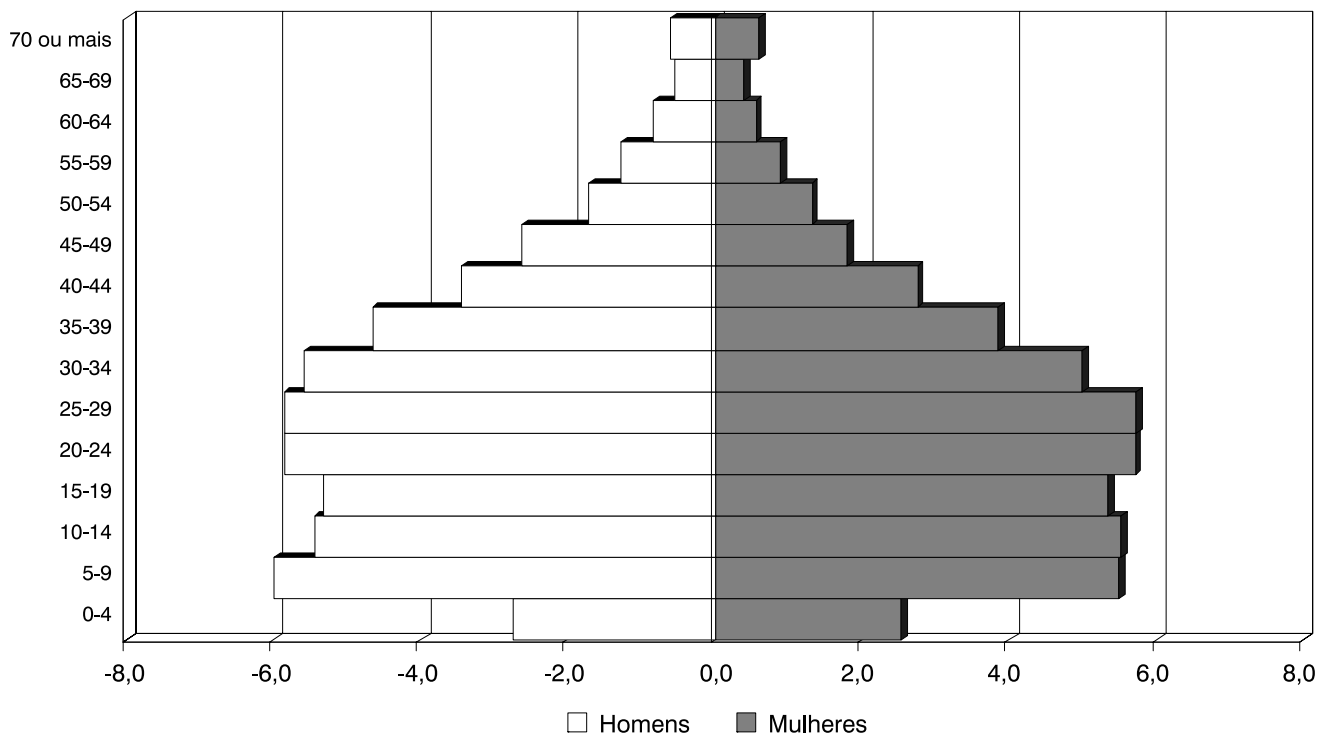

Fonte: IBGE. Censo Demográfico de 2000. Tabulações especiais Nepo/Unicamp.

GRÁFICO 5

Pirâmide etária dos não-migrantes

Estado de Mato Grosso, 2000

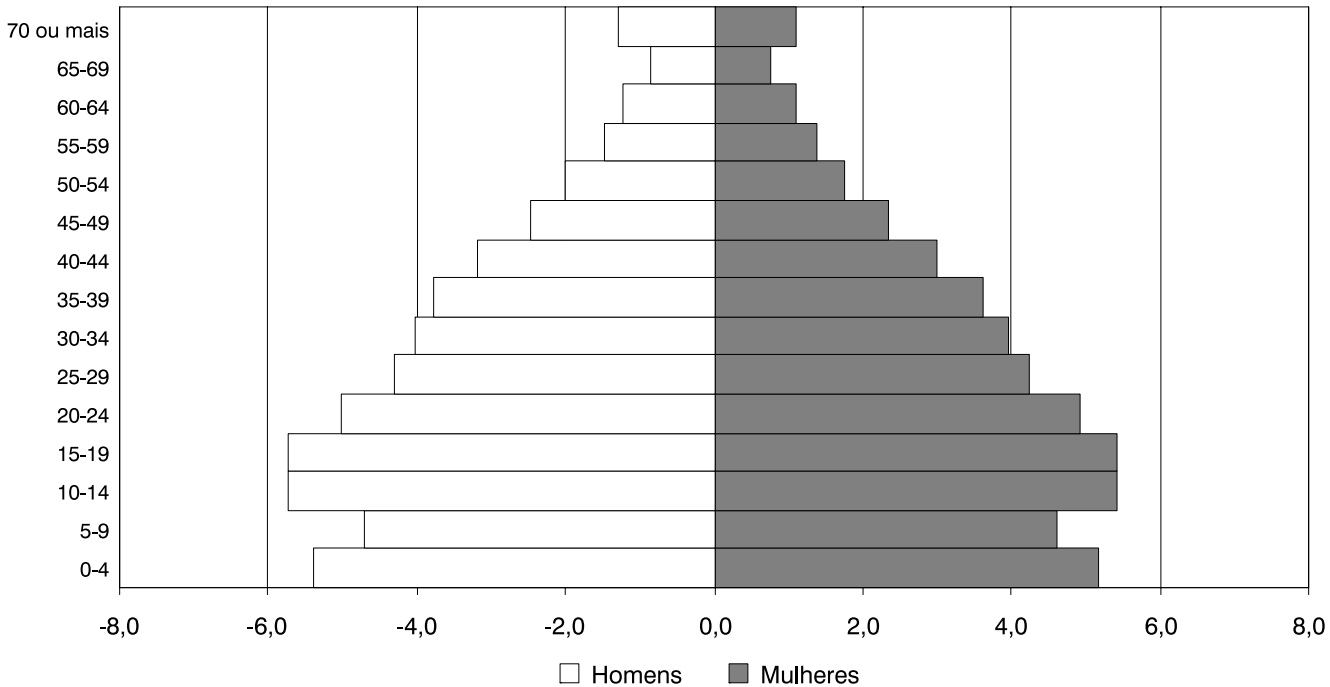

Fonte: IBGE. Censo Demográfico de 2000. Tabulações especiais Nepo/Unicamp. 
TABELA 7

Distribuição das famílias de chefes migrantes interestaduais, por tipo, segundo microrregiões

Estado de Mato Grosso - 1970-1996

Em porcentagem

\begin{tabular}{|c|c|c|c|c|c|c|c|c|c|c|c|c|c|c|c|c|c|c|c|c|c|}
\hline \multirow{2}{*}{ Microrregiões } & \multicolumn{3}{|c|}{ Individual } & \multicolumn{3}{|c|}{ Casal sem Filhos } & \multicolumn{3}{|c|}{ Casal com Filhos } & \multicolumn{3}{|c|}{ Estendida } & \multicolumn{3}{|c|}{ Chefe com Filhos } & \multicolumn{3}{|c|}{ Outras } & \multicolumn{3}{|c|}{ Total ( $\mathrm{N}^{\mathrm{os}}$ absolutos) } \\
\hline & $70 / 80$ & $81 / 91$ & $91 / 00$ & $70 / 80$ & $81 / 91$ & $91 / 00$ & $70 / 80$ & $81 / 91$ & $91 / 00$ & $70 / 80$ & $81 / 91$ & $91 / 00$ & $70 / 80$ & $81 / 91$ & $91 / 00$ & $70 / 80$ & $81 / 91$ & $91 / 00$ & $70 / 80$ & $81 / 91$ & $91 / 00$ \\
\hline Aripuanã & 21,3 & 8,7 & 9,3 & 9,4 & 11,8 & 12,4 & 56,4 & 59,5 & 58,3 & 5,3 & 9,1 & 8,3 & 3,1 & 5,0 & 5,2 & 4,5 & 5,9 & 6,5 & 2.713 & 10.272 & 8.393 \\
\hline Alta Floresta & 6,4 & 6,5 & 9,9 & 11,6 & 11,2 & 14,0 & 65,8 & 55,9 & 54,5 & 8,1 & 10,7 & 6,8 & 3,2 & 6,8 & 6,8 & 4,9 & 8,9 & 7,9 & 4.638 & 12.628 & 4.598 \\
\hline Colíder & 7,3 & 8,2 & 11,0 & 9,7 & 11,1 & 10,5 & 67,2 & 50,7 & 52,5 & 7,1 & 10,7 & 8,8 & 3,5 & 6,9 & 8,8 & 5,2 & 12,5 & 8,5 & 7.581 & 20.836 & 6.861 \\
\hline Parecis & 15,7 & 16,2 & 17,8 & 10,0 & 12,1 & 12,1 & 53,6 & 52,0 & 48,5 & 10,7 & 7,3 & 7,4 & 2,3 & 3,9 & 5,8 & 7,6 & 8,6 & 8,3 & 1.721 & 4.304 & 7.097 \\
\hline Arinos & 8,5 & 5,5 & 10,8 & 10,8 & 11,4 & 13,0 & 67,5 & 62,8 & 59,1 & 7,6 & 7,9 & 5,3 & 3,2 & 6,3 & 6,0 & 2,4 & 6,1 & 5,9 & 3.834 & 5.272 & 3.964 \\
\hline Alto Teles Pires & 9,6 & 11,1 & 8,4 & 7,8 & 10,7 & 13,1 & 64,3 & 58,7 & 56,5 & 12,9 & 8,3 & 7,7 & 1,2 & 3,8 & 5,0 & 4,2 & 7,3 & 9,3 & 1.097 & 7.761 & 10.776 \\
\hline Sinop & 12,4 & 10,0 & 8,4 & 10,7 & 13,0 & 13,8 & 61,5 & 57,3 & 52,6 & 7,6 & 7,5 & 7,9 & 3,4 & 5,5 & 7,6 & 4,4 & 6,6 & 9,7 & 4.427 & 11.085 & 10.662 \\
\hline Paranatinga & 9,2 & 3,7 & 14,1 & 9,8 & 12,2 & 16,9 & 62,6 & 66,0 & 53,1 & 9,7 & 9,3 & 4,7 & 4,7 & 3,3 & 3,8 & 3,9 & 5,5 & 7,2 & 1.555 & 1.430 & 1.152 \\
\hline Norte Araguaia & 17,3 & 10,7 & 13,1 & 9,7 & 9,7 & 12,9 & 51,5 & 54,3 & 50,7 & 8,8 & 10,2 & 7,6 & 4,5 & 7,1 & 6,5 & 8,2 & 8,0 & 9,1 & 2.101 & 5.139 & 7.320 \\
\hline Canarana & 5,3 & 7,7 & 15,1 & 11,4 & 12,6 & 13,0 & 59,7 & 58,6 & 50,6 & 13,1 & 7,9 & 5,5 & 3,5 & 6,1 & 8,4 & 7,0 & 7,1 & 7,4 & 3.935 & 6.072 & 5.176 \\
\hline Médio Araguaia & 8,4 & 9,2 & 13,4 & 8,9 & 10,2 & 12,9 & 55,0 & 48,9 & 45,7 & 13,3 & 8,4 & 6,0 & 6,7 & 11,8 & 13,2 & 7,7 & 11,6 & 8,8 & 3.633 & 3.674 & 3.229 \\
\hline Alto Guaporé & 7,1 & 10,3 & 12,2 & 7,5 & 11,3 & 11,9 & 66,9 & 54,2 & 49,1 & 9,6 & 9,7 & 8,9 & 2,9 & 4,7 & 8,7 & 6,0 & 9,8 & 9,1 & 1.808 & 4.044 & 3.377 \\
\hline Tangará da Serra & 5,7 & 19,3 & 9,2 & 9,4 & 10,3 & 11,0 & 66,8 & 50,4 & 56,8 & 9,9 & 8,4 & 6,8 & 3,5 & 5,3 & 8,4 & 4,7 & 6,3 & 7,8 & 5.666 & 6.165 & 6.863 \\
\hline Jauru & 4,2 & 6,7 & 8,3 & 11,1 & 11,6 & 13,0 & 69,0 & 61,2 & 53,3 & 8,0 & 6,1 & 7,3 & 4,0 & 7,1 & 7,7 & 3,6 & 7,3 & 10,3 & 8.364 & 5.826 & 3.056 \\
\hline Alto Paraguai & 14,1 & 13,3 & 12,9 & 9,7 & 11,7 & 6,7 & 53,3 & 52,6 & 59,7 & 12,7 & 6,5 & 7,1 & 4,9 & 7,2 & 8,4 & 5,2 & 8,7 & 5,4 & 2.047 & 1.235 & 630 \\
\hline Rosário do Oeste & 32,0 & 10,0 & 15,2 & 3,6 & 11,1 & 18,4 & 43,5 & 58,2 & 46,4 & 15,1 & 11,5 & 9,3 & 3,2 & 4,0 & 3,5 & 2,5 & 5,2 & 7,2 & 278 & 478 & 429 \\
\hline Cuiabá & 14,2 & 8,9 & 13,1 & 10,0 & 10,0 & 13,0 & 49,8 & 52,0 & 47,2 & 14,1 & 9,4 & 6,9 & 4,7 & 9,0 & 10,8 & 7,1 & 10,7 & 9,0 & 14.864 & 34.291 & 26.726 \\
\hline Alto Pantanal & 8,4 & 9,5 & 12,4 & 10,2 & 10,9 & 12,9 & 60,4 & 57,9 & 50,2 & 12,7 & 9,0 & 6,0 & 3,3 & 6,2 & 9,1 & 5,0 & 6,4 & 9,5 & 2.218 & 3.218 & 2.472 \\
\hline Primavera do Leste & - & 11,2 & 10,1 & - & 13,9 & 12,0 & - & 52,4 & 52,2 & - & 9,6 & 7,7 & - & 3,0 & 7,3 & - & 9,9 & 10,7 & - & 3.154 & 5.414 \\
\hline Tesouro & 14,6 & 10,8 & 13,1 & 9,6 & 12,6 & 16,8 & 51,1 & 47,9 & 49,4 & 12,8 & 6,2 & 6,8 & 5,4 & 8,5 & 7,6 & 6,5 & 14,1 & 6,3 & 1.960 & 1.957 & 1.482 \\
\hline Rondonópolis & 9,5 & 8,8 & 13,2 & 9,1 & 12,1 & 13,0 & 60,0 & 54,8 & 47,7 & 10,6 & 8,7 & 6,2 & 5,2 & 8,3 & 10,3 & 5,6 & 7,3 & 9,5 & 7.996 & 10.238 & 9.531 \\
\hline Alto Araguaia & 12,5 & 8,8 & 16,9 & 9,1 & 14,5 & 12,4 & 59,5 & 50,1 & 45,2 & 9,8 & 10,5 & 4,9 & 4,8 & 6,7 & 9,8 & 4,2 & 9,4 & 10,8 & 1.159 & 1.486 & 1.274 \\
\hline Total & 10,0 & 9,3 & 11,7 & 10,0 & 11,2 & 12,8 & 60,1 & 54,6 & 51,5 & 10,3 & 9,1 & 7,2 & 4,1 & 6,8 & 8,1 & 5,5 & 8,9 & 8,7 & 83.595 & 60565 & 130.481 \\
\hline
\end{tabular}

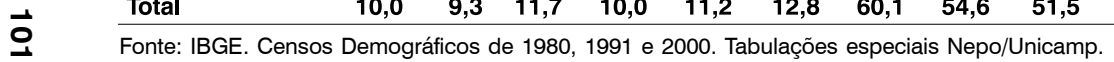


redução da participação desta categoria de arranjo doméstico em favor, particularmente, do tipo "individual".

Do ponto de vista do comportamento das microrregiões, o que se percebe é que a relação entre o perfil dos arranjos domésticos e os momentos de cada área no processo de ocupação demográfica e da fronteira de Mato Grosso é bastante clara. Os dados para as regiões do norte e noroeste matogrossense (Alta Floresta, Aripuanã, Colíder, Arinos, etc.) mostram que, nestas áreas, mesmo em 2000 , a proporção de famílias nucleares era a mais significativa entre os migrantes. A predominância de famílias não se repete no caso das microrregiões com maior dinamismo urbano, como Cuiabá, Rondonópolis e até mesmo Parecis, que, como já se comentou, apresentam grande crescimento demográfico e rápida urbanização, muito provavelmente em função dos efeitos da expansão da soja.

Outro elemento que permite melhor situar a problemática migratória no Estado de Mato Grosso refere-se à forma de inserção produtiva dos chefes migrantes. ${ }^{13}$ A partir desta análise foi possível identificar o progressivo "desmonte" a que foi submetido o Estado no que se refere às suas formas tradicionais de ocupação e em termos demográficos e econômicos.

Entre as principais alterações ocorridas no perfil da migração, nos trinta anos analisados, a que permite maiores inferências quanto aos condicionantes da redução da migração para o Estado é a forte redução da participação relativa da categoria "autônomo ou conta-própria na agropecuária", ${ }^{14}$ no conjunto dos migrantes. Na verdade, associado ao arrefecimento da migração ao longo do período, percebe-se que, enquanto na década de 70 esta categoria absorvia produtivamente $31,4 \%$ dos chefes de família migrantes economicamente ativos, este porcentual reduz-se para algo em torno de $12,9 \%$ em 1991 e $9,6 \%$ em $2000 . .^{15}$

$\mathrm{Na}$ verdade, o impacto das transformações produtivas em Mato Grosso fica ainda mais claro quando estes dados são analisados segundo as microrregiões, uma vez que tal procedimento revela reduções ainda mais dramáticas desta categoria de chefes migrantes, como em Aripuanã (de $39,7 \%$ em 1980 para $25,2 \%$ em 2000), Colíder (de 67,7\% para 24,5\%), Paranatinga (de $51,3 \%$ para $10,6 \%$ ), Jauru (de $54,4 \%$ para 16,2\%) e Tangará da Serra (de 41,3\% para 3,0\%). Um caso interessante a ser também destacado é o de Norte Araguaia, que, nos anos 80 , experimentou um incremento destes migrantes ligados à agricultura familiar, atingindo $40 \%$ do total, sendo que, na década seguinte, este porcentual reduziu-se para $29 \%$. Nesse caso específico, sabe-se que a área entra com mais força como "rota" da fronteira apenas na década de 80 (Gráfico 6).

É interessante ainda notar que, no Estado de Mato Grosso, a tendência apontada para os migrantes também se observa para os "não-migrantes". Como se percebe no Gráfico 7, estes últimos também reduziram sua participação na categoria "autônomos ou conta-própria na agropecuária", indicando que o ocorrido com os migrantes não representa uma situação peculiar, mas sim uma tendência de um Estado que se urbaniza a passos largos e que, portanto, oferece

\footnotetext{
${ }^{13}$ Esta variável foi construída de maneira a espelhar as condições de inserção dos migrantes na estrutura social dos locais de destino. Embora não tenham a pretensão de ser uma proposta de estrutura socioocupacional, as categorias construídas a partir do cruzamento entre o "setor da atividade" e "posição na ocupação" pretendem, de maneira aproximada, revelar a forma como o migrante se insere na estrutura social do Estado, particularmente no que tange ao seu vínculo com as atividades agrícolas e urbanas. Além disso, pode haver um problema de comparabilidade com o Censo de 2000, o qual modificou a forma de captação da população economicamente ativa, embora a informação gerada tenha tentado ficar mais próxima das definições usadas em 1991 e 1980.

${ }^{14}$ Nesse caso particular, acredita-se que, entre as possibilidades oferecidas pelo Censo Demográfico, esta categoria seria a que mais se aproxima da identificação do pequeno proprietário familiar.

${ }^{15}$ É importante alertar para o fato de que, no Censo de 2000 , existe uma possibilidade de que na categoria "conta-própria na agropecuária" estejam também contabilizados os parceiros e meeiros, cuja condição não foi levantada no referido censo. Assim, em comparação com os censos anteriores, os porcentuais apresentados podem estar até sobre estimados, muito embora o peso de parceiros e meeiros historicamente tenha sido pouco representativo no Estado.
} 
GRÁFICO 6

Participação dos "autônomos ou conta-propria na agropecuária" na PEA, segundo microrregiões selecionadas Estado de Mato Grosso - 1970-2000

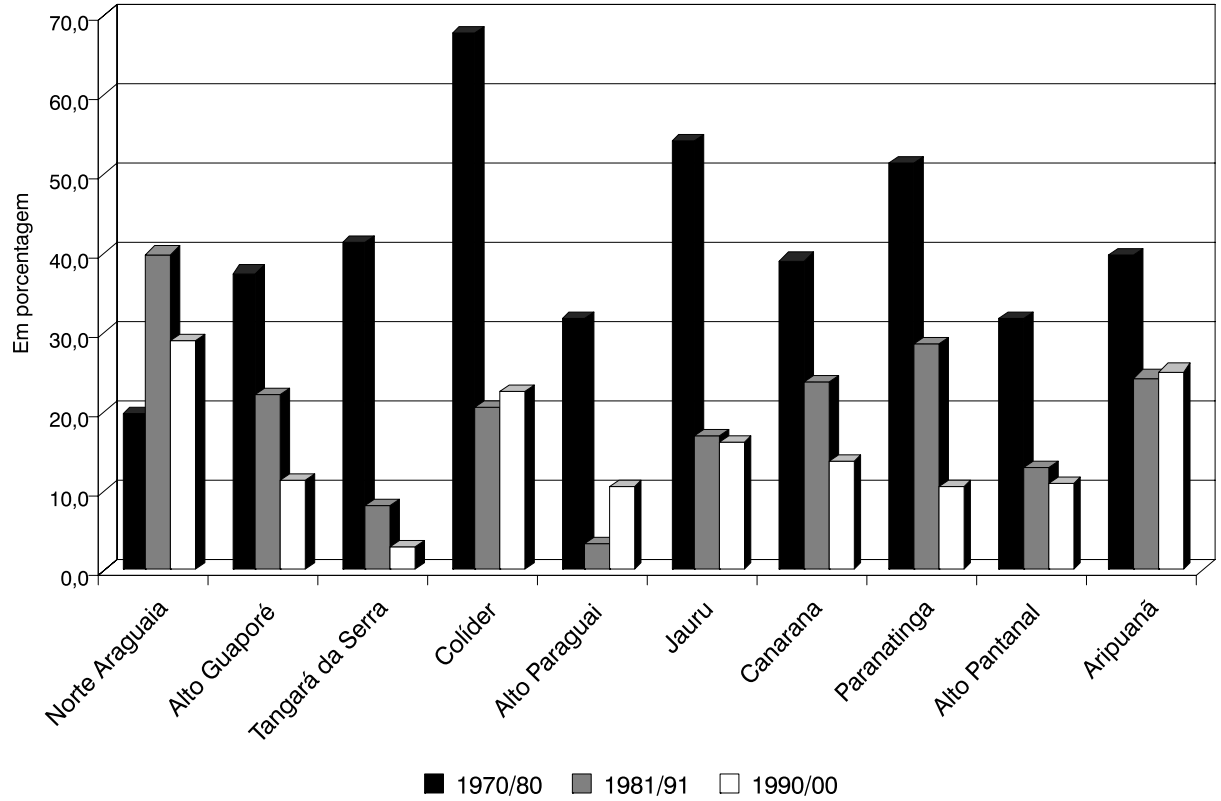

Fonte: IBGE. Censos Demográficos de 1980, 1991 e 2000. Tabulações especiais Nepo/Unicamp.

GRÁFICO 7

Trabalhadores "autônomos ou conta-própria na agropecuária", segundo condição migratória Estado de Mato Grosso - 1980-2000

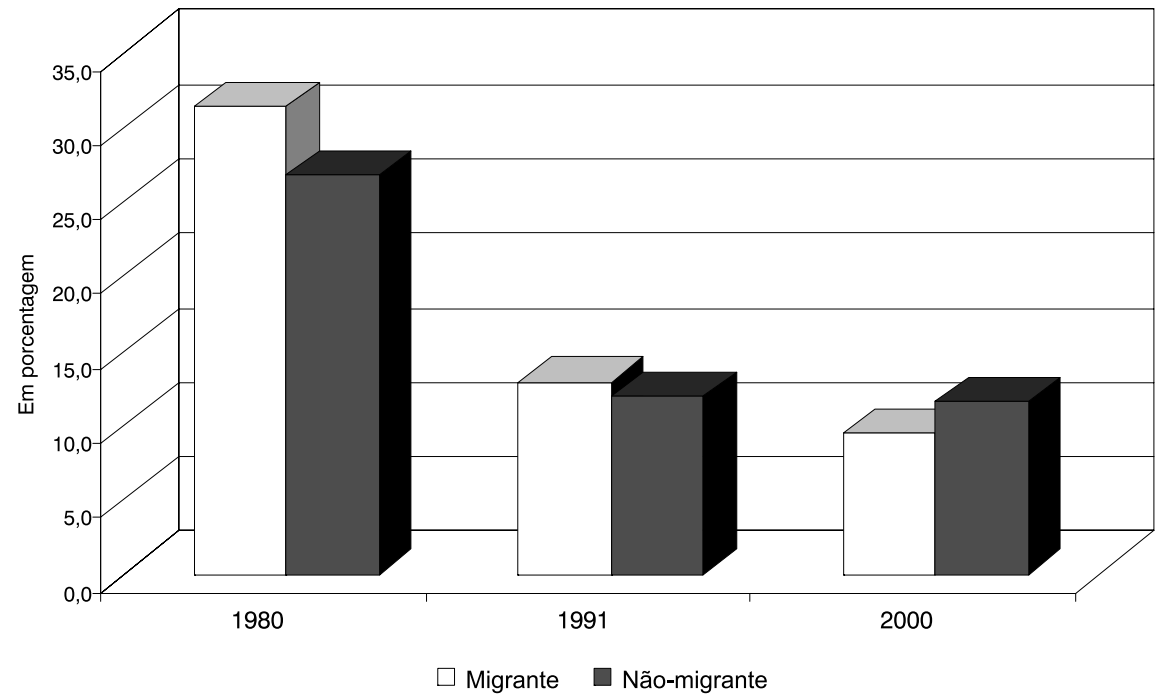

Fonte: IBGE. Censos Demográficos de 1980, 1991 e 2000. Tabulações especiais Nepo/Unicamp. 
poucas alternativas aos seus habitantes, em particular aqueles ligados ao meio rural.

Entre estas alternativas, destacam-se os assentamentos de trabalhadores rurais ligados à Reforma Agrária, que, juntamente com ocupações espontâneas - em geral de pioneiros - têm viabilizado, ou mantido em algum grau, a agricultura familiar no Estado.

Vale destacar ainda o caso de Sinop, onde a atividade industrial (leia-se madeireiras) absorvia, em 1991, mais de $40 \%$ dos migrantes, situação que denota a força desse tipo de atividade nesta área. Porém, na visita a campo, os discursos de políticos da região já sugerem sinais de fraqueza dessa indústria, devido, sobretudo, ao esgotamento das reservas florestais mais próximas. Assim, os investimentos estão se destinando ao desenvolvimento de atividades mais diversificadas, como indústrias de móveis e ampliação do setor de serviços, além da introdução da agricultura capitalizada, principalmente de soja e arroz.

A despeito da importância da pecuária no Estado, o porcentual de migrantes que trabalham nesta atividade é relativamente pequeno, chegando em 1991, a pouco mais de $4 \%$ e aumentando para quase $11 \%$ em 2000. Na verdade, verifica-se que, nas duas últimas décadas, a maior parte dos chefes migrantes estava vinculada a atividades tipicamente urbanas - "Comércio e Serviços" e "Indústria" -, que geravam trabalho a 23,4\% e $27,7 \%$ dos chefes migrantes em 1991 e 2000 , respectivamente, contra apenas $16,3 \%$ no começo do período em estudo.

Tais dados mostram sinais de que o "potencial atrativo" de Mato Grosso como área de fronteira não consolidada, progressivamente, vai se esgotando, fato que se reflete nas formas possíveis de inserção dos migrantes, em geral trabalhadores rurais, pequenos produtores e descapitalizados, a quem restam poucas alternativas nos centros urbanos ou nos assentamentos ligados à Reforma Agrária.

\section{Conclusões}

Como uma das últimas áreas de fronteira agrícola no país e, portanto, como uma das poucas alternativas para a migração de pessoas ligadas ao campo, o Estado de Mato Grosso, até meados dos anos 80 , cumpriu um papel importante no processo de redistribuição espacial da população brasileira. Contudo, sua trajetória nessa condição foi uma das mais curtas em relação aos Estados do Centro-Oeste, em função de uma rápida e intensa transformação produtiva e do conseqüente acirramento do processo de concentração fundiária, ao qual foi exposto nas décadas de 80 e 90 .

Em um misto de desenvolvimento econômico em ritmo intenso e progressivo "fechamento" das fronteiras agrícolas pioneiras, o Estado de Mato Grosso, em menos de 20 anos, deixa de ser um palco de possibilidades para milhares de brasileiros em busca de alternativas de reprodução social no meio rural, para se converter paulatinamente em uma alternativa de grandes possibilidades econômicas.

Os dados analisados neste estudo mostram não apenas a redução do ímpeto migratório para o Estado, como também as relações entre este comportamento e as mudanças nas formas de inserção dos migrantes, que espelham o processo de "urbanização da fronteira" e a grande desarticulação das formas de ocupação que possibilitaram o "desbravamento" de boa parte de seu território.

Mesmo existindo poucas possibilidades concretas para a manutenção de Mato Grosso como uma área de atração migratória, ainda há muitas regiões do Estado que se configuram como grandes alternativas para a absorção do grande contingente de pessoas que exercem atividades ligadas à terra. Hoje em dia, regiões do noroeste do Estado, por exemplo, são aquelas que mais crescem em termos demográficos e boa parte deste crescimento se deve a novos núcleos rurais que surgem. Entretanto, pode-se perceber que proporção significativa do crescimento demográfico estadual acontece nos centros urbanos, em especial nos maiores, como Cuiabá, Rondonópolis e Sinop.

A alternativa dos assentamentos rurais tem sido uma possibilidade concreta de reverter parte desse processo de "urbanização forçada" de grandes parcelas de 
migrantes, e até mesmo de nativos e residentes mais antigos do Estado. Na verdade, pode-se afirmar que o processo de ocupação demográfica de Mato Grosso, particularmente no que diz respeito ao papel das pequenas propriedades baseadas na agricultura familiar, provavelmente teria sido ainda mais desarticulado caso não existissem os programas de assentamentos rurais.

Estes projetos podem ser encontrados em praticamente todos os municípios de Mato Grosso. No entanto, é fundamental que a forma de implantação e o gerenciamento destes projetos sejam repensados de maneira a torná-los uma saída "real" para aqueles que pretendem viver no e do rural.

As atividades econômicas hegemônicas (pecuária e soja) deixam suas marcas em praticamente todas as áreas existentes, via de regra, implicando considerável desruralização e inchamento urbano, que, na maior parte do território matogrossense, não possui condições de reter o excedente populacional. Este contínuo "movimento da fronteira" é percebido pela avaliação das tendências demográficas das várias microrregiões do Estado.

Não se trata aqui de fazer qualquer apologia a possíveis efeitos negativos da expansão capitalista da agricultura, até porque ela é uma realidade e um dos grandes pilares do desenvolvimento econômico nacional. $\mathrm{Na}$ verdade, como se tentou mostrar neste estudo, em algumas áreas de Mato Grosso o efeito da soja até se deu de maneira contrária, ou seja, viabilizando e dinamizando a ocupação demográfica. No entanto, não há como negar que a forma como se dá a apropriação da riqueza gerada por esta nova atividade não tem garantido uma distribuição da renda adequada e nem, por conseqüência, implicado uma meIhoria das condições de vida da população, em particular daquelas pessoas ou famílias que desejariam garantir sua reprodução social fora dos centros urbanos.

No entanto, considerando a trajetória econômica e demográfica mais recente do Mato Grosso, fica claro que esta atividade, combinada com a grande hegemonia, em termos espaciais, da pecuária, deixa poucas alternativas viáveis para a continuidade do intenso processo de ocupação, como fora observado nas décadas passadas. Além disso, não se pode perder de vista que parte deste processo deveu-se à atividade garimpeira, que, embora não esgotada totalmente no Estado, hoje se desenvolve preponderantemente a partir de grandes empresas mineradoras, não mais movimentando consideráveis volumes de migrantes.

Resta, portanto, pensar na força dos maiores centros urbanos, como Cuiabá, Rondonópolis e talvez Sinop, que, no entanto, não parecem possuir uma estrutura produtiva tão diversificada para fornecer alternativas suficientes para a atração de migrantes interestaduais. Até porque estes últimos, certamente, são precedidos pelos migrantes intra-estaduais "deslocados" em volumes cada vez maiores das áreas rurais, até então ocupadas no âmbito da expansão da fronteira.

Diante deste quadro, considera-se que o Estado de Mato Grosso caminha progressivamente para o esgotamento de sua condição de fronteira agrícola, deixando de ser uma alternativa para os migrantes. Talvez projetos concretos, como a pavimentação do trecho da Belém-Brasília no Pará - que facilitaria o escoamento da produção -, ou ainda aqueles mais distantes da realidade atual, como o desmembramento de Mato Grosso, pudessem no futuro dar novos rumos à dinâmica demográfica do Estado. Entretanto, nesse momento é difícil imaginar sequer a manutenção do poder atrativo dos anos 80 e, conseqüentemente, um desempenho migratório muito além daquele possibilitado por alguns centros urbanos.

As análises realizadas permitem, portanto, vislumbrar algumas alternativas para o processo de ocupação demográfica de Mato Grosso. Deve-se reconhecer que este processo encontra-se em franca modificação e, certamente, será influenciado por opções dos governos estadual e federal com relação a questões bastante complexas, e por vezes contraditórias, para um país capitalista dependente como é o Brasil: conciliar o desenvolvimento econômico com o desenvolvimento humano e ainda a conservação ambiental. 


\section{Referências bibliográficas}

BECKER, B. K. Fronteiras amazônicas no início do século XXI. In: SEMINÁRIO MUDANCAS AMBIENTAIS GLOBAIS: PERSPECTIVAS BRASILEIRAS. Campinas: Nepo/Unicamp, 2000.

CARVALHO, J. A. M.; MACHADO, C. C. Quesitos sobre migrações no Censo Demográfico de 1991. Revista Brasileira de Estudos de População, v.9, n.1, 1992.

CUNHA, J. M. P. Migrações no Centro-Oeste brasileiro: as tendências e características do período de 1986-1996. ENCONTRO DE DEMOGRAFIA DA REGIÃO CENTROOESTE, 2. Anais... Brasília: Codeplan/ FNUAP, 2000.

\section{A migração no Centro-Oeste} brasileiro no período 1970-96: o esgotamento de um processo de ocupação. Campinas: Nepo/Pronex/Unicamp, 2002.

Migração e transformações produtivas na fronteira: o caso do Mato Grosso. ENCONTRO NACIONAL DE ESTUDOS POPULACIONAIS, 13, Ouro Preto, 2002. Anais... Belo Horizonte: ABEP, 2002.

Trinta anos de redistribuição espacial da população no Brasil: principais tendências e a trajetória do Estado de São Paulo. São Paulo em Perspectiva, São Paulo, Fundação Seade, 2004, no prelo.

CUNHA, J. M. P.; AZEVEDO, M. M. Demographic and socio-cultural aspects of population mobility in Brazil. In: HOGAN, D. J. (Org.). Population change in Brazil: contemporary perspectives. Campinas: Nepo/Unicamp, 2001.

CUNHA, J. M. P.; SILVEIRA, F. A. Região Centro-Oeste: o esgotamento de um processo de ocupação? Campinas: Pronex, Nepo/Unicamp, 1999. Mimeografado.

DINIZ, A. M. A migração e evolução da fronteira agrícola. ENCONTRO DA ASSOCIAÇÃO BRASILEIRA DE ESTUDOS POPULACIOANAIS, 13, Ouro Preto, 2002. Anais... Belo Horizonte: ABEP, 2002.

Frontier evolution and mobility in volatile settements of the Brazilian
Amazon. Tese de doutorado. Arizona: Arizona State University, 2002.

EGLER, C. A. G. Mudanças recentes no uso e na cobertura da terra no Brasil. In: SEMINÁRIO MUDANÇAS AMBIENTAIS GLOBAIS: PERSPECTIVAS BRASILEIRAS. Campinas: Nepo/Unicamp, 2000. Disponível em: <http://www.laget.igeo.ufrj.br/ egler/pdf/Uso Completo.pdf $>$. Acesso em: 23 abr. 2004.

FERREIRA, E. de C.; FERNÁNDEZ, A. J. C.; SILVA, E. P. A reconstrução dos assentamentos rurais em Mato Grosso. In: MEDEIROS, L. S.; LEITE, S. (Orgs.). A formação dos assentamentos rurais no Brasil: processos sociais e políticas públicas. Rio de Janeiro: Editora da UFRJ, [s.d.].

GOMES, M. A. V. Zoneamento sócioeconômico ecológico: diagnóstico sócioeconômico ecológico do estado de Mato Grosso e assistência técnica na formulação da $2^{\circ}$ aproximação. Cuiabá: Governo do Estado do Mato Grosso/Seplan/Bird, 2000 (situação fundiária - parte 2: sistematização das informações temáticas - nível compilatório).

IPEA/FJN. Transformações recentes da fronteira agrícola e implicações para a dinâmica espacial do Brasil. Recife, 1997.

LEITE, S. Assentamentos rurais: um balanço da experiência brasileira. Rio de Janeiro, 1998. Disponível em: <www.nead. gov.br>. Acesso em: 13 dez. 2001.

MARTINE, G. A redistribuição espacial da população brasileira durante a década de 80. Brasília: Ipea, 1994 (Texto para discussão, 329).

MATTEI, L. A evolução do emprego agrícola no Brasil. São Paulo: Abet, v. 4, 1998 (Coleção Mercado de Trabalho).

OLIVEIRA, A. U. de. A fronteira amazônica matogrossense: grilagem, corrupção e violência. Tese de livre-docência. São Paulo, USP, 1997.

SEPLAN - Secretaria de Planejamento e Coordenação. Zoneamento econômico e 
ambiental do Estado do Mato Grosso. Mato Grosso: Seplan, 1999. CD-ROM (Socioeconômico e Jurídico Institucional).

SINGER, P. Migrações internas: considerações teóricas sobre o seu estudo. In: MOURA, H. (Org.). Migração interna: textos selecionados. Fortaleza: Banco do Nordeste do Brasil, 1980.
SYDENSTRICKER, J. M. N. Parceleiros de Machadinho: história migratória e as interações entre a dinâmica demográfica e o ciclo agrícola em Rondônia. Dissertação de mestrado. Campinas: IFCH/Unicamp, 1992.

VEIGA, J. E. da. Cidades imaginárias: 0 Brasil é menos urbano do que se calcula. Campinas: Editora Autores Associados, 2002.

\begin{abstract}
Migratory dynamics and the occupation process in central-western Brazil: The case of the State of Mato Grosso
\end{abstract}

The State of Mato Grosso is one of the last frontier areas in Brazil, and still shows some potential for populations that continue to seek alternatives for migration. Concurrently with the process of "urbanization of the frontier," one can see other phenomena in the state that are having strong impacts on the opening up of new possibilities for realigning the population in the territory, such as small farm settlements and new pioneering projects, which would have positive impacts for the continued demographic occupation of the state. After having gone through an intense process of occupation until the mid-1980s, Mato Grosso's demographic growth slowed down considerably. At the same time, however, it also continued to show relative dynamism in general. The present article is based on analyses of data from the Demographic and Agricultural Censuses and from interviews held in Mato Grosso, and analyzes migratory trends in the state and their impacts on the process of occupation of the state in recent years. Special emphasis is given to the behavior of several areas that are representative of the most important processes now underway. The author also seeks to locate these processes of change in the patterns of economic occupation. The analyses show strong association between the two phenomena, namely, on the one hand, the impact of extensive land-use activities such as cattle raising, soybeans, and cotton in reducing the possibilities for absorbing migrants in the rural areas and, on the other, the "compensating" effects of land reform settlements.

Key words: Internal migration. Agricultural frontier. Determinants of migration. State of Mato Grosso.

Recebido para publicação em 16/11/2005 Aceito para publicação em 17/03/2006. 
